\title{
Computational design of double-layer cathode coatings in all- solid-state batteries
}

Chuhong Wang, ${ }^{1}$ Koutarou Aoyagi, ${ }^{1}$ Tim Mueller ${ }^{1, *}$

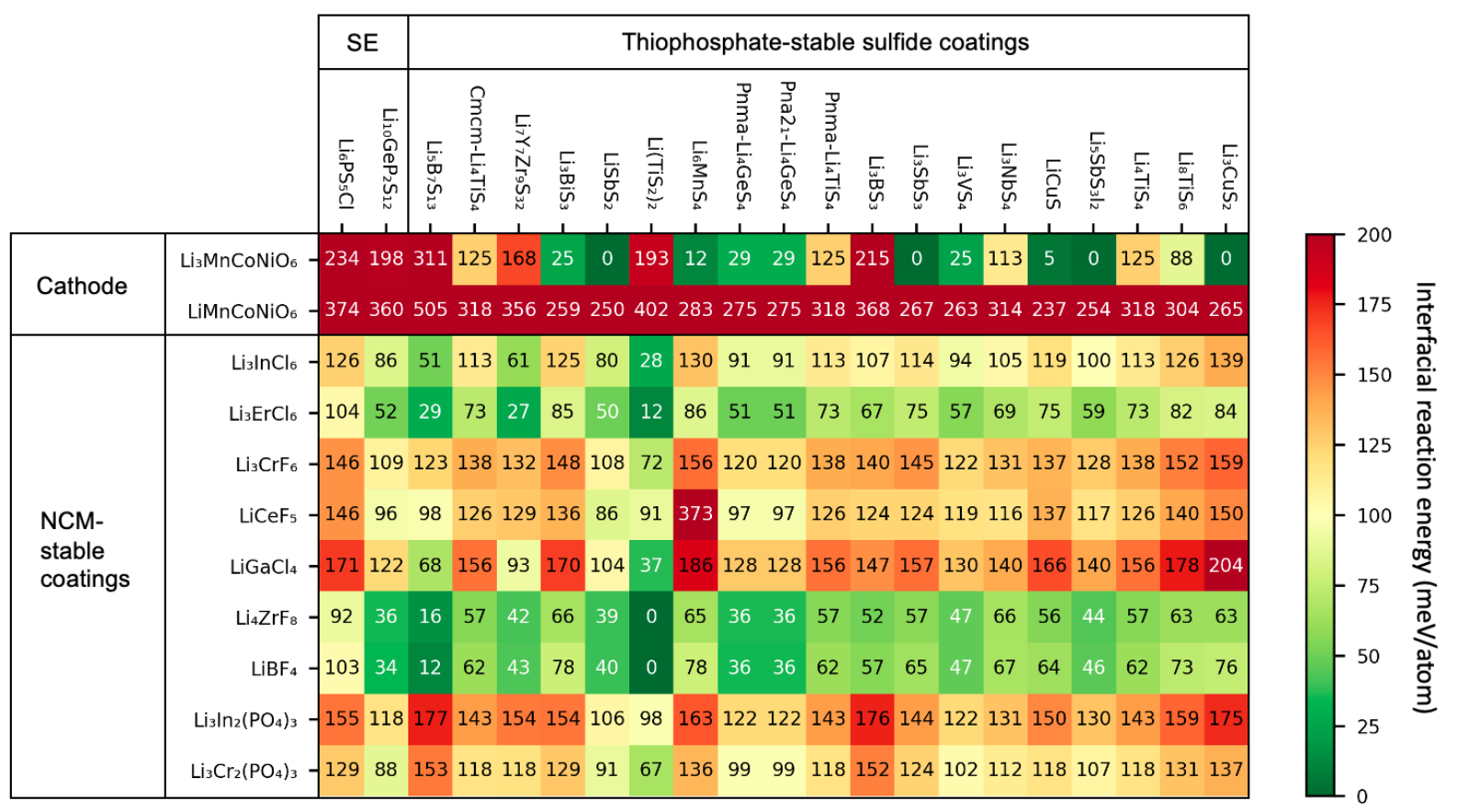

${ }^{1}$ Department of Materials Science and Engineering, Johns Hopkins University, Baltimore, Maryland 21218, United States

*Corresponding Author

Tim Mueller

Department of Materials Science and Engineering

Johns Hopkins University

3400 N. Charles St.

Baltimore, MD 21218 USA

(410)516-5779

tmueller@jhu.edu 


\begin{abstract}
All-solid-state lithium-ion batteries have great potential for improved energy and power density compared to conventional lithium-ion batteries. With extensive research efforts devoted to the development of inorganic superionic conductors, lithium thiophosphates stand out due to their high ionic conductivity and room-temperature processability. However battery rate performance still suffers from increased impedance attributed to the interfacial reactions between thiophosphate electrolyte and oxide electrodes. Stabilizing the interfaces with a protective coating layer has been proposed as a solution to the interfacial problem, but it is rare for a material to simultaneously exhibit fast ionic conductivity and chemical stability at battery interfaces. Here, we propose a double-layer coating design comprising a sulfide-based layer adjacent to the thiophosphate electrolyte accompanied by a layer that is stable against the oxide cathode. Based on a highthroughput thermodynamic stability screen and active learning molecular dynamics simulations, we identify several sulfide + halide couples that potentially outperform the known coating materials in interfacial stability as well as ionic conductivity. Several halides we identify have been recently identified as novel solid electrolyte candidates. We highlight the integration of roomtemperature fast ionic conductors $\mathrm{Li}_{5} \mathrm{~B}_{7} \mathrm{~S}_{13}\left(137 \mathrm{mS} \mathrm{cm}{ }^{-1}\right), \mathrm{Li}_{7} \mathrm{Y}_{7} \mathrm{Zr}_{9} \mathrm{~S}_{32}\left(6.5 \mathrm{mS} \mathrm{cm} \mathrm{cm}^{-1}\right)$, and $\mathrm{Li}\left(\mathrm{TiS}_{2}\right)_{2}\left(0.0008 \mathrm{mS} \mathrm{cm}{ }^{-1}\right)$ which potentially reduces interfacial reactivity with minor loss of charge transfer rate through the thiophosphate electrolyte.
\end{abstract}

\title{
1.INTRODUCTION
}

Rechargeable batteries are a crucial component of efforts to reduce carbon emissions. Lithium ion batteries have dominated the market for portable electronics due to their high efficiency, low cost, high capacity, lack of memory effect, and long cycle life. ${ }^{1,2}$ The introduction of new solid-state electrolyte chemistries has the potential to further improve battery performance. Solid electrolytes enable the construction of bipolar cells with improved power and energy density. ${ }^{3,4}$ In addition, by mechanically suppressing dendrite formation and growth, solid electrolytes may enable higher specific energy through the use of Li-metal anodes. ${ }^{5,6}$

Several structural families of solid Li-ion conductors have been identified over the past several decades. ${ }^{7}$ Among the solid electrolyte candidates, lithium thiophosphates (e.g. $\mathrm{Li}_{6} \mathrm{PS}_{5} \mathrm{Cl}, \beta-\mathrm{Li}_{3} \mathrm{PS}_{4}$, $\mathrm{Li}_{10} \mathrm{GeP}_{2} \mathrm{~S}_{12}$, and various thiophosphate glasses) have attracted the most attention for their superior Li-ion conductivity of $10^{-3}$ to $10^{-2} \mathrm{~S} \mathrm{~cm}^{-1}$ at $25^{\circ} \mathrm{C}$ with a high lithium transference number of $\sim 1$ and good deformability to compensate for volume changes associated with Li removal and insertion in the electrodes. ${ }^{8-10}$ One of the main obstacles hindering the realization of highperformance solid-state batteries is the high internal resistance at the interface between the solid electrolyte and the active electrode materials. Both theoretical predictions and experimental characterizations have shown that the interfacial reactions between the thiophosphate-based electrolyte and the oxide-based cathode produce Li-ion insulating phases, which lead to significant degradation of the rate performance. ${ }^{11-17}$ Mitigation of the internal impedance is critical to the commercialization of all-solid-state batteries. The most efficient method to achieve this is through a protective coating between the cathode active material and the electrolyte, which may improve rate performance and cyclability by limiting or eliminating unwanted reactions at solid-solid interfaces. 
To stabilize the cathode-electrolyte interface, thus inhibiting undesirable side reactions, ideal interfacial coating materials should be thermodynamically stable against both the electrode and the electrolyte. Commonly applied coatings are primarily ternary oxides such as $\mathrm{LiNbO}_{3},{ }^{18,}, 19$ $\mathrm{Li}_{4} \mathrm{Ti}_{5} \mathrm{O}_{12},{ }^{20} \mathrm{Li}_{2} \mathrm{SiO}_{3},{ }^{21} \mathrm{Li}_{4} \mathrm{SiO}_{4},{ }^{22} \mathrm{Li}_{2} \mathrm{ZrO}_{3}, \mathrm{LiTaO}_{3}{ }^{23}$ and $\mathrm{Li}_{3} \mathrm{PO}_{4}{ }^{24}$, along with composites such as $\mathrm{Li}_{2} \mathrm{BO}_{3}-\mathrm{Li}_{2} \mathrm{CO}_{3},{ }^{25} \mathrm{LiInO}_{2}-\mathrm{LiI},{ }^{26}$ and $\mathrm{Li}_{2} \mathrm{O}-\mathrm{ZrO}_{2} .{ }^{27}$ Based on first-principle studies, these oxidebased coatings effectively extend the electrochemical stability window of the solid electrolyte. ${ }^{28}$ Automated computational screening of vast crystalline material databases enables efficient identification of additional coating candidates with high interfacial stability, thus greatly accelerating the discovery of candidate coating materials..$^{12,29-33}$

In addition to the thermodynamic considerations, high Li-ion conductivity is also a key factor in achieving high rate capability. The identification of a single coating material that has all desirable properties, including high stability and high lithium-ion conductivity, has not yet been achieved. Previous studies have suggested that the scarcity of ideal coating materials may be explained by the inverse correlation between Li-ion conductivity and electrochemical stability. ${ }^{12,34}$ Searching for the few outliers in a broad chemical space poses a challenge for material discovery.

To overcome this limitation, we explore a double-layer coating strategy to ease the stringent requirements on a single material, therefore enhancing the likelihood of finding suitable combinations of properties. In a previous study, we predicted that the interphase components that form stable interfaces with the thiophosphate electrolyte are likely to be either phosphates or sulfides. ${ }^{17}$ The formation of phosphates is attributed to reductive decomposition due to $\mathrm{P}^{+5} / \mathrm{P}^{-3}$ redox reactions at potentials of about $1.7 \mathrm{~V}$ versus $\mathrm{Li}^{+} / \mathrm{Li}$. This may be prevented by a protective oxide-free sulfide layer that inhibits the oxidation of phosphorous in the electrolyte. ${ }^{17}$ In addition, we found several sulfide-based interphase components such as $\mathrm{Li}_{4} \mathrm{GeS}_{4}$ and $\mathrm{Li}_{3} \mathrm{PS}_{4}$ with relatively high Li-ion conductivity, consistent with the fact that sulfides generally possess higher ionic conductivity than oxides due to larger and more polarizable $\mathrm{S}^{2-}$ than $\mathrm{O}^{2-} \cdot 35$ Given their electrochemical properties and ionic conductivity, we search among the lithium sulfides for coatings that are thermodynamically compatible with the thiophosphate electrolytes $\mathrm{Li}_{6} \mathrm{PS}_{5} \mathrm{Cl}$ and $\mathrm{Li}_{10} \mathrm{GeP}_{2} \mathrm{~S}_{12}$ while maintaining rate capabilities.

In comparison to thermodynamic compatibility, which can rapidly be evaluated by theoretical phase diagram prediction, diffusion kinetics in candidate coating materials are more difficult to investigate in a systematic, high-throughput way. The rate of Li-ion diffusion through commonly used coating materials is typically several orders of magnitude slower than through solid electrolytes. ${ }^{36}$ Widely used approaches such as the climbing image nudged elastic band method ${ }^{37}$, 38 or ab-initio molecular dynamics are either difficult to automate or prohibitively expensive for screening coating candidates. ${ }^{39}$ There has recently been great interest in using machine learning to accelerate the development of rechargeable batteries, ${ }^{40}$ and here we employ a recently developed scheme using machine-learned interatomic potentials ${ }^{41}$ to circumvent the problem of slow ionic conductor screening. To preserve the accuracy of the machine-learned potential and minimize the 
cost of generating training data, molecular dynamics simulations are coupled with on-the-fly machine learning (LOTF-MD). Based on the activation energies for diffusion computed using LOTF-MD, we identify 14 sulfides predicted to have high lithium-ion conductivity, of which $\mathrm{Li}_{5} \mathrm{~B}_{7} \mathrm{~S}_{13}, \mathrm{Li}_{4} \mathrm{TiS}_{4}$ (with Cmcm symmetry), $\mathrm{Li}_{7} \mathrm{Y}_{7} \mathrm{Zr}_{9} \mathrm{~S}_{32}, \mathrm{Li}_{3} \mathrm{BiS}_{3}$ are recognized for exceptionally high Li-ion conductivity comparable to the leading thiophosphate-based solid electrolytes. To our knowledge, several sulfides such as $\mathrm{Li}_{4} \mathrm{TiS}_{4}(\mathrm{Cmcm}), \mathrm{Li}_{7} \mathrm{Y}_{7} \mathrm{Zr}_{9} \mathrm{~S}_{32}, \mathrm{Li}_{3} \mathrm{BiS}_{3}$ and $\mathrm{LiSbS}_{2}$ are characterized in terms of viable $\mathrm{Li}^{+}$conduction the first time.

According to previous interphase studies, sulfides are susceptible to oxidation decomposition when exposed to oxide-based cathodes. ${ }^{14,17,42}$ To optimize the interfacial rate performance, a coating layer that conducts conducting lithium ions at sufficiently high speed and eliminates interfacial reactivity must be placed between the sulfide layer and the cathode. Here we focus on the cathode material $\mathrm{LiNi}_{1 / 3} \mathrm{Mn}_{1 / 3} \mathrm{Co}_{1 / 3} \mathrm{O}_{2}(\mathrm{NCM})$, which is an attractive alternative to $\mathrm{LiCoO}_{2}$ due to its relatively low cost, high capacity, and better thermal stability. ${ }^{43} \mathrm{NCM}$ is currently one of the most promising cathode candidates for commercial applications, but sulfides in contact with NCM usually result in high Li-ion impedance attributed to the formation of sulfates. ${ }^{17,}{ }^{42}$ From a firstprinciple database of over $1500 \mathrm{Li}$-containing crystalline materials, we find 11 candidate NCMstable coatings that are predicted to have sufficiently low activation barriers for Li diffusion. Most of the identified NCM coating candidates are halides, followed by a small fraction of polyanionic oxides. Among the lithium halides we find, the composition of $\mathrm{Li}_{3} \mathrm{MX}_{6}(\mathrm{X}=\mathrm{Cl}, \mathrm{F})$ is predicted to exhibit the highest ionic conductivity. These have recently attracted attention as electrolyte candidates for application in all-solid-state lithium batteries owing to high room-temperature ionic conductivity, wide electrochemical windows, and good thermodynamic compatibility with the oxide cathode. ${ }^{44}$

Guided by the interfacial compatibility, we suggest several pairs of sulfide + halide double-layer coatings with low chemical reactivity at the interface and reasonably high ionic conductivity. Notably, the ultrafast ionic conductors $\mathrm{Li}_{5} \mathrm{~B}_{7} \mathrm{~S}_{13}$ and $\mathrm{Li}_{7} \mathrm{Y}_{7} \mathrm{Zr}_{9} \mathrm{~S}_{32}$ are distinguished for their outstanding chemical stability with the cathode-stable coating layers. We suggest a half-cell architecture comprising of the sulfide + halide coating, thiophosphate electrolyte, and NCM cathode with overall activation energy for diffusion of less than $0.5 \mathrm{eV}$ through all components, and chemical reactivity no less than $-30 \mathrm{meV} /$ atom at all interfaces. This battery design may maintain the high rate capability and capacity of the state-of-art electrolytes and cathodes while preventing interfacial degradation. Additionally, with the discovery of several superior ionic conductors comparable to thiophosphate electrolytes, we discuss the possibility of simplifying the battery architecture by replacing the thiophosphate electrolyte with sulfide-based or halide-based superionic conductors.

\section{METHODS}

2.1. Thermodynamic calculations of phase stability and interfacial stability 
Thermodynamic stability of materials can be estimated by constructing convex hulls of DFTcalculated formation energies with respect to composition. We have assessed the thermodynamic stability of each compound using energies of all compounds in the chemical space from the Materials Project database. ${ }^{45}$ The convex hull was constructed using the pymatgen software package ${ }^{46}$. The difference between the energy of the compound and the energy of the convex hull at the same composition corresponds to the driving force of decomposition, which can be used to quantify the thermodynamic stability of a material. ${ }^{47}$ Phases that are on the convex hull are predicted to be stable at $0 \mathrm{~K}$. However, many phases with formation energies above the calculated $0 \mathrm{~K}$ convex hull exist in nature for extended periods of time, as a result of either DFT error, ${ }^{48}$ entropic stabilization, or phase metastability preserved by a high kinetic barrier of decomposition. Based on previous analysis of these factors, ${ }^{47,48}$ we used $30 \mathrm{meV} /$ atom above the convex hull as the pre-screening criterion for phase stability.

Two phases can coexist in local thermodynamic equilibrium if they are connected by a tie-line on the phase diagram. Thermodynamically compatible interfaces are identified using the interfacial reaction energy methodology developed by Richards et al. ${ }^{49}$, in which the reactivity is quantified by determining at which fraction of two phases the reaction driving force becomes maximal. An interfacial reaction energy of zero indicates that the two phases can form a thermodynamically stable interface. The pymatgen software package ${ }^{46}$ was used to assess interfacial stability.

\subsection{Ab initio molecular dynamics}

$\mathrm{Ab}$ initio molecular dynamic (AIMD) simulations were performed using the Perdew-BurkErnzerhof generalized gradient approximation exchange-correlation functional ${ }^{50}$ and projector augmented wave ${ }^{51}$ potentials as listed in the Supplementary Information Table S1-S2. We used a plane wave energy cut-off of $400 \mathrm{eV}$ and a minimal $\Gamma$-centered $1 \times 1 \times 1 k$-point mesh which has been shown to provide a satisfactory balance between computational accuracy and cost. $^{52,53}$ Computations were performed with spin polarization and with magnetic ions initialized in a high-

spin ferromagnetic state for materials containing transition metal atoms. Non-spin-polarized calculations were performed otherwise. A time step of $2 \mathrm{fs}$ was adopted. The supercell sizes were constructed to ensure there were at least $9 \AA$ between neighboring images ${ }^{52}$ to avoid periodic boundary effects. The lattice parameter was fixed at that of the cell fully relaxed at $0 \mathrm{~K}$.

For each material, 15 ps AIMD was carried out at $1000 \mathrm{~K}$ in the NVT ensemble. In each AIMD run, the first 2 ps was used for equilibration and then a 13 ps dynamic trajectory was generated to compute the mean squared displacement of the $\mathrm{Li}$ ions. In the case that the maximal mean-squaredisplacement of lithium has exceeded $9 \AA^{2}$ (chosen based on a typical lithium hopping distance of $3 \AA)^{17}$ over 13 ps at elevated temperature, the material was considered to be a potential Li-ion conductor at room temperature and additional molecular dynamics simulations were performed with moment tensor potentials trained on the AIMD trajectory as described in the next section. Otherwise, the material was estimated to be ionically insulating at room temperature and no further calculations were performed to determine its ionic conductivity.

2.3. Learning on-the-fly molecular dynamics 
The ionic conductivity of each material passing the AIMD screening was computed using a scheme we developed recently ${ }^{41}$ based on learning-on-the-fly molecular dynamics (LOTF-MD) and moment tensor potentials (MTPs) ${ }^{54}$ The use of this scheme enables us to gather orders of magnitude more data than can be achieved using AIMD with little loss of accuracy in the calculated energies, resulting in greatly reduced statistical variance in the estimated ionic conductivity. Mean absolute validation errors for the trained potentials on a representative group of coating candidates were $7 \mathrm{meV}$ / atom for energies and $56 \mathrm{meV} / \AA$ for components of the forces (Table S4). For each structure the MTP was initially trained on 13 ps ( 2 fs per time step) of the AIMD simulation at $1000 \mathrm{~K}$. The molecular dynamics simulations used to evaluate ionic conductivity were performed with the trained MTP in LAMMPS. ${ }^{55}$ The interface between moment tensor potential molecular dynamics and DFT geometry optimization was carried out by the Machine Learning of Interatomic Potentials (MLIP) software package. ${ }^{56}$ The MTP cutoff radius and the maximum level of basis functions, $l e v_{\max }$ were chosen to be $5.0 \AA$ and 10, respectively. Details of the active learning criteria, validation error of energies and forces on various crystalline structures as well as experimental benchmark results can be found in our previous report. ${ }^{41}$ In this study, the simulation temperature was initialized at $1000 \mathrm{~K}$ for each material and decremented by $50 \mathrm{~K}$ until the diffusivity was so low that the total mean squared displacement did not reach $2000 \AA^{2}$ within $200 \mathrm{~ns}$. Each MD run lasted for at least $4 \mathrm{~ns}$ each until the total mean square displacement of $\mathrm{Li}^{+}$reached $2000 \AA^{2}$, which has been reported by He, X. F., et al. ${ }^{39}$ to be a sufficient sample size for accurate statistical analysis. To identify the onset of possible melting, we calculated the mean squared displacement of species other than lithium. We determined that melting occurred if the mean squared displacement of nonlithium species exceeded $3 \AA^{2}$. If melting was detected, we decreased the simulation temperature until the structure remained intact during the molecular dynamics run. The lowest five qualifying temperatures were used to fit an Arrhenius relationship to determine the activation energy for diffusion and estimate the room-temperature diffusivity. The room-temperature conductivity $\sigma_{300 \mathrm{~K}}$ was calculated using the Nernst-Einstein relation under the assumption that the Haven ratio is equal to one: ${ }^{57,58}$

$$
\sigma_{300 K}=\frac{n e^{2} z^{2}}{k_{B} T} D_{300 K}
$$

where $n$ is the volume density of the diffusing species, $e$ is the unit electron charge, $z$ is the charge of the ionic conductor (here $1 \mathrm{for}^{\mathrm{L}}{ }^{+}$), and $D_{300 \mathrm{~K}}$ is the extrapolated room-temperature tracer diffusivity.

\subsection{Coating candidates screening criteria}

Our screening workflow (Figure 1) was designed to efficiently use computational resources by carrying out relatively fast predictions on a vast pool of candidates, followed by expensive $\mathrm{Li}$ conductivity calculations limited to those highly promising compounds satisfying the criteria of high Li content, phase stability, and interfacial stability with either the cathode or electrolyte. Considering all known solid electrolytes contain $\mathrm{Li}$, we searched among the compounds with at least $10 \% \mathrm{Li}$ by composition. We screened for materials with energies no more than $30 \mathrm{meV} /$ atom 
above the convex hull. Among those, we calculated the interfacial reaction energy with the solid electrolyte and with the cathode in both discharged state $\mathrm{LiNi}_{1 / 3} \mathrm{Co}_{1 / 3} \mathrm{Mn}_{1 / 3} \mathrm{O}_{2}$ and charged state $\mathrm{Li}_{1 / 3} \mathrm{Ni}_{1 / 3} \mathrm{Co}_{1 / 3} \mathrm{Mn}_{1 / 3} \mathrm{O}_{2} .{ }^{59}$ By the criterion of interfacial reaction energy no less than $-30 \mathrm{meV} /$ atom, we identified coating candidates compatible with NCM cathode (Table S1) and compatible with the solid electrolytes (Table S2). Among compounds meeting the above requirements, we performed diffusion calculations using LOTF-MD and selected those computed with activation energies less than $0.7 \mathrm{eV}$ to be the coating candidates. This activation energy cutoff is roughly equivalent to requiring room-temperature ionic conductivity on the order of $10^{-5} \mathrm{mS} / \mathrm{cm}$ or greater (see Section S1), which is near the lower bound for acceptable conductivities for thin coating layers we estimated in our previous work. ${ }^{41}$ This activation energy is lower than that of some commonly employed crystalline coating materials such as $\mathrm{Li}_{3} \mathrm{PO}_{4}(1.1-1.3 \mathrm{eV}),{ }^{60,61} \mathrm{Al}_{2} \mathrm{O}_{3}(1.15 \mathrm{eV}),{ }^{62}$ and $\mathrm{Li}_{2} \mathrm{CO}_{3}(0.8 \mathrm{eV}),{ }^{63}$ but it is possible that diffusion through these coating occurs through grain boundaries or defects in the crystal structure.

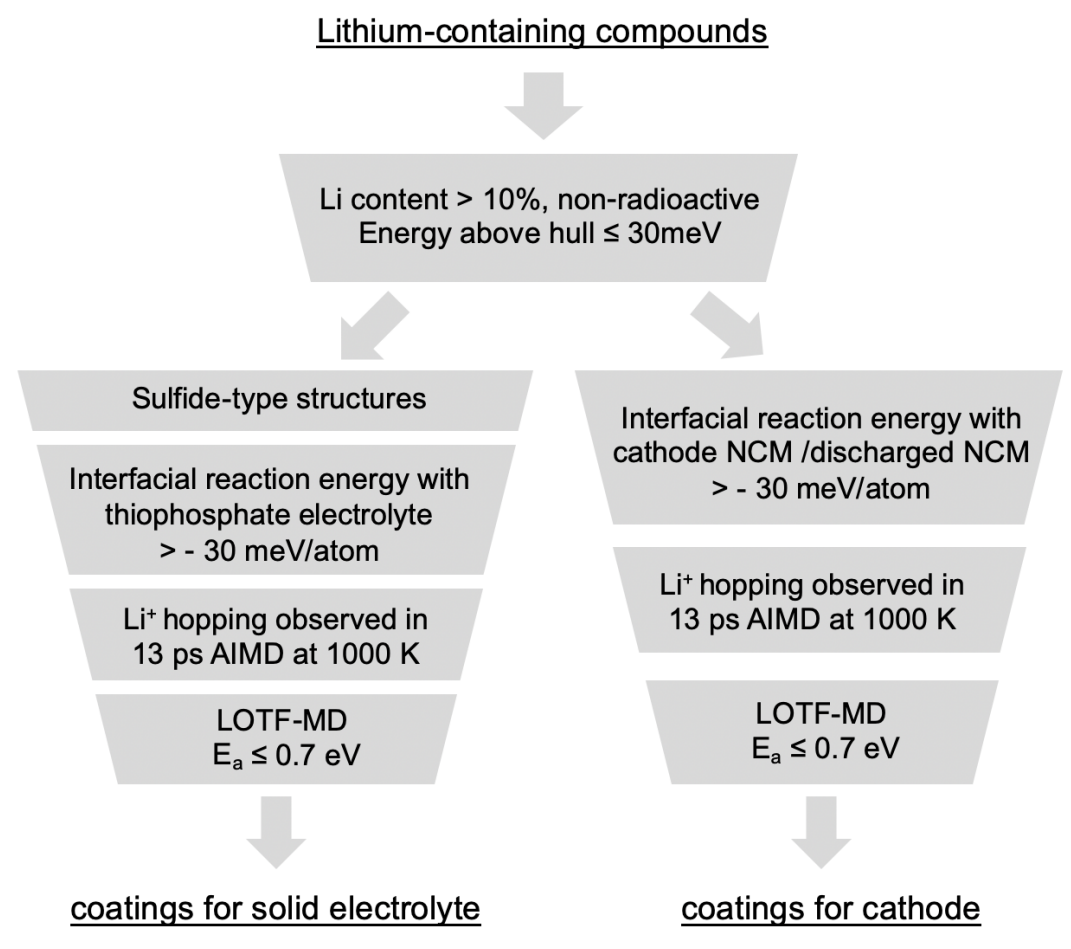

Figure 1. Workflow of high-throughput screening of Li-containing compounds to identify candidate coatings for the lithium thiophosphate electrolyte (left) and NCM cathode (right).

\section{RESULTS AND DISCUSSION}

The initial screening in terms of Li content, phase stability and interfacial stability was conducted rapidly with DFT-calculated energies from the Materials Project database. From 1545 Licontaining crystalline materials, we found 181 materials that are thermodynamically compatible with the cathode in both the charged and discharged states, and 93 materials that are thermodynamically compatible with the solid electrolytes. The same set of 93 materials was stable 
against both LGPS and $\mathrm{Li}_{6} \mathrm{PS}_{5} \mathrm{Cl}$. Within the reduced pool of materials, we have performed the two-step molecular dynamics calculation as described in Methods sections 2.2 and 2.3. Based on the Li-ion displacement during 15 ps AIMD simulation at $1000 \mathrm{~K}, 238$ materials were predicted to be ionic insulators at room temperature. We computed the diffusion activation energy of the remaining 36 materials with LOTF-MD at multiple temperatures and identified 25 materials that meet the criteria of chemical compatibility and sufficiently high Li-ion conductivity.

(a)

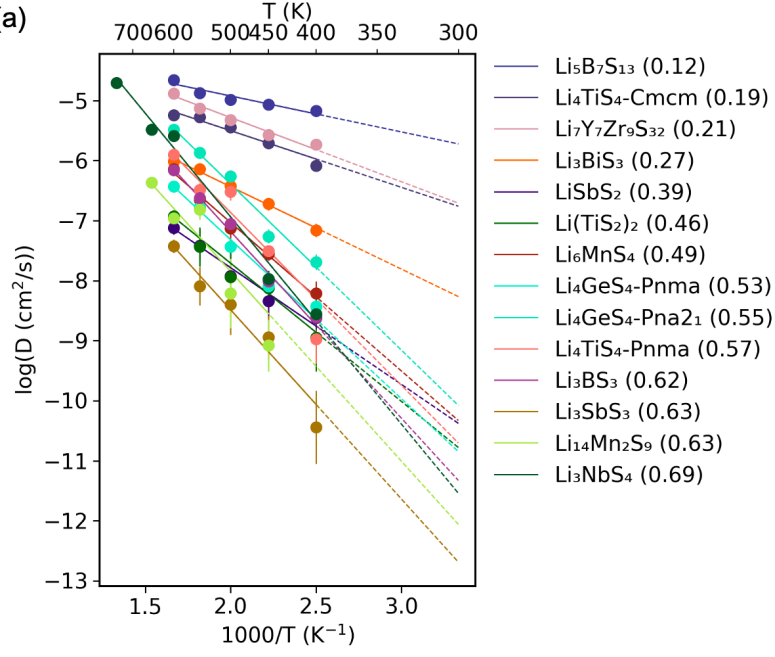

(b)

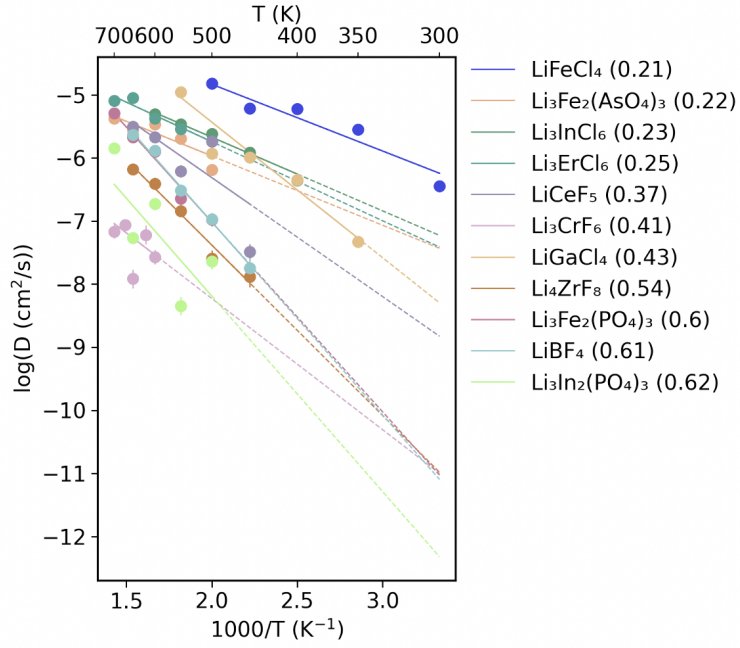

Figure 2. Diffusion coefficients calculated from LOTF-MD for (a) 14 sulfide coating candidates (b) 11 NCM cathode coating candidates. The diffusivity extrapolated to room temperature for each material is shown as a dashed line of the same color. Structures with the same composition are distinguished by space groups in the legend. The activation energies computed from the slope of the fitting line are in the legend (in brackets) in $\mathrm{eV}$.

From the 93 pre-screened sulfides, we identified 14 ionic conductors with room-temperature conductivity higher than $10^{-5} \mathrm{mS} / \mathrm{cm}$. Diffusivities computed by LOTF-MD are displayed on the Arrhenius plot in Figure 2a. The activation energy and ionic conductivity extrapolated to room temperature along with the literature reported values for these 14 sulfides are listed in Table 1. Among these candidates are $\mathrm{Li}_{4} \mathrm{GeS}_{4}, \mathrm{Li}_{5} \mathrm{~B}_{7} \mathrm{~S}_{13}, \mathrm{Li}_{3} \mathrm{BS}_{3}$ and $\mathrm{Li}_{3} \mathrm{SbS}_{3}$, which are known lithiumion conductors. The first three have been previously suggested in the literature as interface coatings for solid-state batteries. ${ }^{64,65}$ In experiments, improved cycling performance was observed in $\mathrm{Li}_{4} \mathrm{SnS}_{4}$ (isostructural to $\mathrm{Li}_{4} \mathrm{GeS}_{4}$ )-coated $\mathrm{LiCoO}_{2}$ compared with pristine $\mathrm{LiCoO}_{2}$ in contact with the LGPS electrolyte. ${ }^{66}$

The identified sulfide coating materials effectively extend the electrochemical stability window with respect to phosphorous oxidation (Figure 3a). Despite the passivation of phosphorous, the sulfide coating cannot completely eliminate the reactivity with the oxide cathode. At high electrochemical potentials, the decomposition of thiophosphates involves the oxidation of sulfur, 
which likewise contributes to the decomposition of sulfide coatings, as shown in Figure $3 \mathrm{~b}$. To protect the sulfide layers from oxidation reactions, we searched for a second layer that could stabilize the interface against the oxide-based cathode. Among the 181 compounds stable against the NCM cathode, 11 have diffusion activation energies lower than $0.7 \mathrm{eV}$ as calculated using LOTF-MD. Good linearity has been achieved in the Arrhenius plots (Figure 2b) for all NCM coatings with the exceptions of $\mathrm{LiBF}_{4}$ and $\mathrm{Li}_{3} \mathrm{In}_{2}\left(\mathrm{PO}_{4}\right)_{3}$, for which we only collected data in a limited range of high temperatures because of their low diffusivities. Given these low diffusivities even at the $700 \mathrm{~K}$, the highest simulation temperature, we don't expect these two materials to be competitive candidates. The calculated oxidation voltage limits of all 11 coatings are listed in Table S3. Aside from three polyanionic compounds $\mathrm{Li}_{3} \mathrm{X}_{2}\left(\mathrm{YO}_{4}\right)_{3}(\mathrm{X}=\mathrm{Fe}, \mathrm{In} ; \mathrm{Y}=\mathrm{P}$, As), the majority are chlorides and fluorides (Figure $2 \mathrm{~b}$ and Table 2). Halides have been recently recognized as promising materials for applications in solid-state batteries due to their desirable balance between electrochemical stability and ionic conductivity. ${ }^{44} \mathrm{We}$ exclude $\mathrm{Li}_{3} \mathrm{Fe}_{2}\left(\mathrm{AsO}_{4}\right)_{3}$ and $\mathrm{LiFeCl}_{4}$ as coating candidates because of the toxicity of the arsenate and the low predicted melting temperature $(\leq 400 \mathrm{~K})$ of $\mathrm{LiFeCl}_{4}$.

(a)

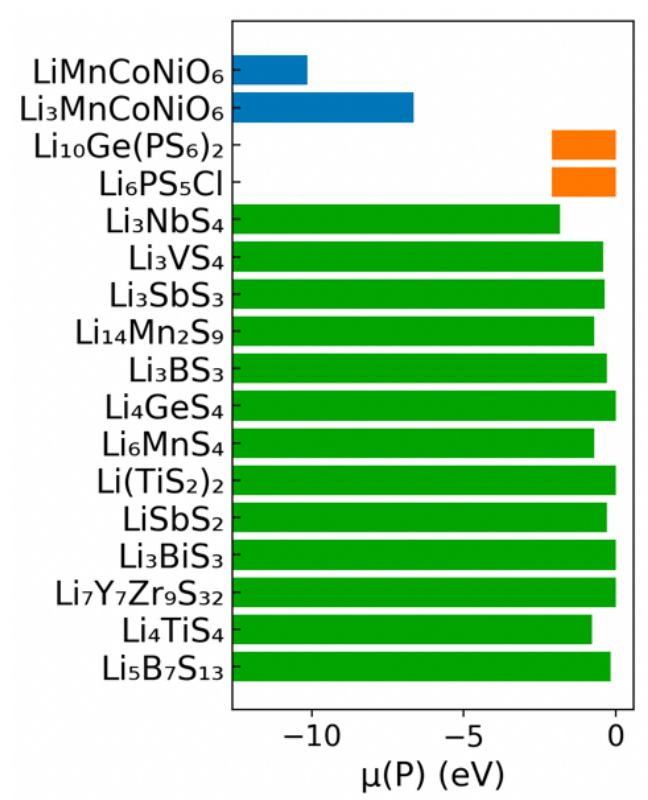

(b)

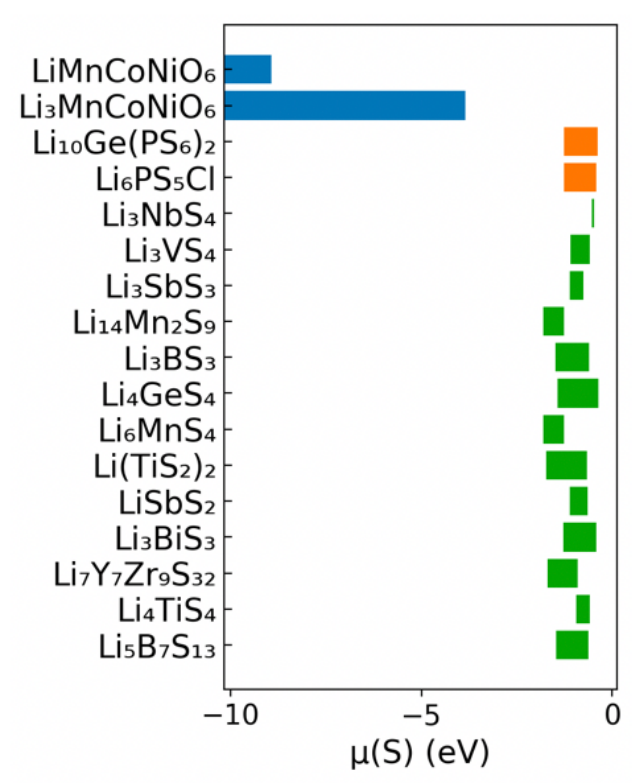

Figure 3. Stability windows with respect to the chemical potential of (a) phosphorous (b) sulfur in NCM (blue), thiophosphate electrolytes (orange), and sulfide-based coating candidates (green). 
Table 1. Calculated activation energies for diffusion $\left(E_{a}\right)$ in 14 sulfide-based electrolyte coating candidates computed by LOTF-MD. Literature values are listed where available.

\begin{tabular}{|c|c|c|c|c|c|}
\hline $\begin{array}{l}\text { Materials } \\
\text { Project entry } \\
\text { id }\end{array}$ & Composition & Space group & $\begin{array}{l}\text { LOTF-MD- } \\
\text { computed Ea } \\
(\mathrm{eV})\end{array}$ & $\begin{array}{l}\text { Extrapolated } \\
300 \mathrm{~K} \\
\text { conductivity } \\
(\mathrm{mS} / \mathrm{cm})\end{array}$ & $\begin{array}{l}\text { Literature reported } \\
\mathrm{Li}^{+} \text {conductivity at } \\
300 \mathrm{~K} \text { if available }\end{array}$ \\
\hline mp-532413 & $\mathrm{Li}_{5} \mathrm{~B}_{7} \mathrm{~S}_{13}$ & $\mathrm{Cc}$ & $0.12 \pm 0.01$ & 137.924 & $74 \mathrm{mS} / \mathrm{cm}^{67}$ \\
\hline mp-756811 & $\mathrm{Li}_{4} \mathrm{TiS}_{4}$ & $\mathrm{Cmcm}$ & $0.19 \pm 0.02$ & 24.448 & \\
\hline mp-767467 & $\mathrm{Li}_{7} \mathrm{Y}_{7} \mathrm{Zr}_{9} \mathrm{~S}_{32}$ & P1 & $0.21 \pm 0.02$ & 6.504 & \\
\hline mp-753720 & $\mathrm{Li}_{3} \mathrm{BiS}_{3}$ & $\mathrm{R}-3$ & $0.27 \pm 0.03$ & 0.695 & \\
\hline mp-14591 & $\mathrm{LiSbS}_{2}$ & $\mathrm{R}-3$ & $0.39 \pm 0.07$ & 0.003 & \\
\hline mp-1045384 & $\mathrm{Li}\left(\mathrm{TiS}_{2}\right)_{2}$ & Fd-3m & $0.46 \pm 0.09$ & 0.0008 & \\
\hline mp-756490 & $\mathrm{Li}_{6} \mathrm{MnS}_{4}$ & $\mathrm{P} 4_{2} / \mathrm{nmc}$ & $0.49 \pm 0.04$ & 0.0092 & \\
\hline mp-30249 & $\mathrm{Li}_{4} \mathrm{GeS}_{4}$ & Pnma & $0.53 \pm 0.03$ & 0.0020 & $2.0 \times 10^{-4} \mathrm{mS} / \mathrm{cm}^{68}$ \\
\hline mp-1222582 & $\mathrm{Li}_{4} \mathrm{GeS}_{4}$ & Pna $2_{1}$ & $0.55 \pm 0.03$ & 0.0121 & \\
\hline mp-766540 & $\mathrm{Li}_{4} \mathrm{TiS}_{4}$ & Pnma & $0.57 \pm 0.04$ & 0.0028 & \\
\hline $\mathrm{mp}-5614$ & $\mathrm{Li}_{3} \mathrm{BS}_{3}$ & Pnma & $0.62 \pm 0.04$ & 0.0007 & $0.0031-9.7 \mathrm{mS} / \mathrm{cm}^{64}$ \\
\hline mp-756198 & $\mathrm{Li}_{14} \mathrm{Mn}_{2} \mathrm{~S}_{9}$ & $\mathrm{P}-3$ & $0.63 \pm 0.09$ & 0.0002 & \\
\hline mp-1194339 & $\mathrm{Li}_{3} \mathrm{SbS}_{3}$ & $\mathrm{Pna}_{1}$ & $0.63 \pm 0.1$ & $2.73 \times 10^{-5}$ & $1.6 \times 10^{-6} \mathrm{mS} / \mathrm{cm}^{69}$ \\
\hline mp-755309 & $\mathrm{Li}_{3} \mathrm{NbS}_{4}$ & P-43m & $0.69 \pm 0.03$ & 0.0002 & \\
\hline
\end{tabular}

Table 2. Calculated activation energies for diffusion $\left(E_{a}\right)$ in 11 cathode coating candidates computed by LOTF-MD. Literature values are listed where available.

\begin{tabular}{|l|l|l|l|l|l|}
\hline $\begin{array}{l}\text { Materials } \\
\text { Project entry } \\
\text { id }\end{array}$ & Composition & Space group & $\begin{array}{l}\text { LOTF-MD- } \\
\text { computed Ea } \\
(\mathrm{eV})\end{array}$ & $\begin{array}{l}\text { Extrapolated } \\
\text { 300 K conductivity } \\
(\mathrm{mS} / \mathrm{cm})\end{array}$ & $\begin{array}{l}\text { Literature value of } \\
\mathrm{Li}^{+} \text {conductivity at } \\
\text { 300 K or Ea if } \\
\text { available }\end{array}$ \\
\hline $\mathrm{mp}-556256$ & $\mathrm{Li}_{3} \mathrm{Fe}_{2}\left(\mathrm{AsO}_{4}\right)_{3}$ & $\mathrm{P} 2_{1} / \mathrm{c}$ & $0.22 \pm 0.03$ & 2.7632 & \\
\hline $\mathrm{mp}-676109$ & $\mathrm{Li}_{3} \mathrm{InCl}_{6}$ & $\mathrm{C} 2$ & $0.23 \pm 0.02$ & 4.9162 & $0.05-0.3 \mathrm{mS} / \mathrm{cm}^{70}$ \\
\hline $\mathrm{mp}-676361$ & $\mathrm{Li}_{3} \mathrm{ErCl}_{6}$ & $\mathrm{P} 321$ & $0.25 \pm 0.02$ & 3.3038 & $1.49 \mathrm{mS} / \mathrm{cm}^{71}$ \\
\hline$m p-1210931$ & $\mathrm{LiFeCl}_{4}$ & $\mathrm{P} 2_{1} / \mathrm{c}$ & $0.28 \pm 0.02$ & 16.5844 & \\
\hline$m p-561396$ & $\mathrm{Li}_{3} \mathrm{CrF}_{6}$ & $\mathrm{C} 2 / \mathrm{c}$ & $0.41 \pm 0.12$ & 0.0017 & \\
\hline$m p-1195868$ & $\mathrm{LiCeF}_{5}$ & $\mathrm{I} 4_{1} / \mathrm{a}$ & $0.37 \pm 0.03$ & 0.0998 & \\
\hline$m p-28341$ & $\mathrm{LiGaCl}_{4}$ & $\mathrm{P} 2_{1} / \mathrm{c}$ & $0.43 \pm 0.02$ & 0.1945 & \\
\hline$m p-9308$ & $\mathrm{Li}_{4} \mathrm{ZrF}_{8}$ & $\mathrm{Pnma}$ & $0.54 \pm 0.04$ & 0.0019 & $\mathrm{E}_{\mathrm{a}}=0.22 \mathrm{eV}^{72}$ \\
\hline$m p-31788$ & $\mathrm{Li}_{3} \mathrm{Fe}_{2}\left(\mathrm{PO}_{4}\right)_{3}$ & $\mathrm{P} 2_{1} / \mathrm{c}$ & $0.6 \pm 0.03$ & 0.00076 & $3 \times 10^{-6} \mathrm{mS} / \mathrm{cm}^{73}$ \\
\hline$m p-12403$ & $\mathrm{LiBF}_{4}$ & $\mathrm{P} 321$ & $0.61 \pm 0.04$ & 0.00062 & \\
\hline$m p-6425$ & $\mathrm{Li}_{3} I_{2}\left(\mathrm{PO}_{4}\right)_{3}$ & $\mathrm{R}-3$ & $0.62 \pm 0.05$ & $3.5 \times 10^{-5}$ & $\mathrm{E}_{\mathrm{a}}=0.58 \mathrm{eV}^{74}$ \\
\hline
\end{tabular}

Having identified promising coating candidates for the electrolyte and the cathode, we next evaluated the interfacial stability between pairs of coatings that could be used to create a double- 
layer coating (Figure 4). The coatings identified by our screen generally reduce the thermodynamic driving force for interfacial reactions compared to direct contact between the cathode material and the electrolyte. The sulfide coatings $\mathrm{Li}_{5} \mathrm{~B}_{7} \mathrm{~S}_{13}, \mathrm{Li}_{7} \mathrm{Y}_{7} \mathrm{Zr}_{9} \mathrm{~S}_{32}$ and $\mathrm{Li}\left(\mathrm{TiS}_{2}\right)_{2}$ have particularly high compatibility with coating materials for the NCM cathode. We identify eight coating combinations that reduce the maximum magnitude of the interfacial reaction energy from $374 \mathrm{meV}$ with $\mathrm{Li}_{6} \mathrm{PS}_{5} \mathrm{Cl}$ and $360 \mathrm{meV} /$ atom with LGPS to lower than $30 \mathrm{meV} /$ atom. Four of these pairs, $\mathrm{Li}_{5} \mathrm{~B}_{7} \mathrm{~S}_{13}-\mathrm{Li}_{3} \mathrm{ErCl}_{6}, \mathrm{Li}\left(\mathrm{TiS}_{2}\right)_{2}-\mathrm{Li}_{3} \mathrm{InCl}_{6}, \mathrm{Li}_{7} \mathrm{Y}_{7} \mathrm{Zr}_{9} \mathrm{~S}_{32}-\mathrm{Li}_{3} \mathrm{ErCl}_{6}$, and $\mathrm{Li}\left(\mathrm{TiS}_{2}\right)_{2}-$ $\mathrm{Li}_{3} \mathrm{ErCl}_{6}$ are predicted to have high ionic conductivity, close to those of the solid electrolytes. Interfaces between sulfides and halides may be more likely to be stable than interfaces between sulfides and oxides due the relative scarcity of compounds that contains $\mathrm{Li}, \mathrm{S}$, and $(\mathrm{Cl}$ or $\mathrm{F})$ compared to lithium-containing sulfates. ${ }^{45}$

Due to the moderate ionic conductivity of commonly employed coatings, deposition thickness at the nanometer scale is often required to achieve competitive rate performance. ${ }^{36}$ The coating should also be thick enough to be electronically insulating and protect the electrolyte from the extreme chemical potential of the cathode. Several coating techniques have been investigated to balance these factors and create high-quality coatings in an economically viable way..$^{24,75-77}$ In comparison, some of the double-layer coating designs we propose in this study are predicted to have high ionic conductivity comparable to that of the solid electrolyte. Thus it may be possible to relax the thickness of the coatings to the micrometer scale without significant loss in rate capability, simplifying the production of all-solid-state batteries.

Several candidates from our coating material screen exhibit excellent properties for solid electrolytes. Given the predicted outstanding ionic conductivity and electrochemical stability of $\mathrm{Li}_{5} \mathrm{~B}_{7} \mathrm{~S}_{13}$ and $\mathrm{Li}_{7} \mathrm{Y}_{7} \mathrm{Zr}_{9} \mathrm{~S}_{32}$, they are potential alternatives for the best-known thiophosphate-based solid-state electrolyte materials, including $\mathrm{Li}_{10} \mathrm{GeP}_{2} \mathrm{~S}_{12}$ and $\mathrm{Li}_{6} \mathrm{PS}_{5} \mathrm{Cl}$. Therefore, along with half cells consisting of thiophosphate SE $\mid$ sulfide-halide coatings $\mid$ cathode, we suggest that the phosphorous-free sulfide $\mathrm{SE} \mid$ halide $\mid$ cathode (sulfide $=\mathrm{Li}_{5} \mathrm{~B}_{7} \mathrm{~S}_{13}, \mathrm{Li}_{7} \mathrm{Y}_{7} \mathrm{Zr}_{9} \mathrm{~S}_{32}$ ) may offer comparable or improved performance and simplify the manufacturing process. On the anode side, the sulfide-based electrolyte candidates exhibit interfacial reactivity similar to that with the thiophosphate electrolyte (Table 3), suggesting that if these materials were to be used as electrolytes, anode coatings may be necessary. 


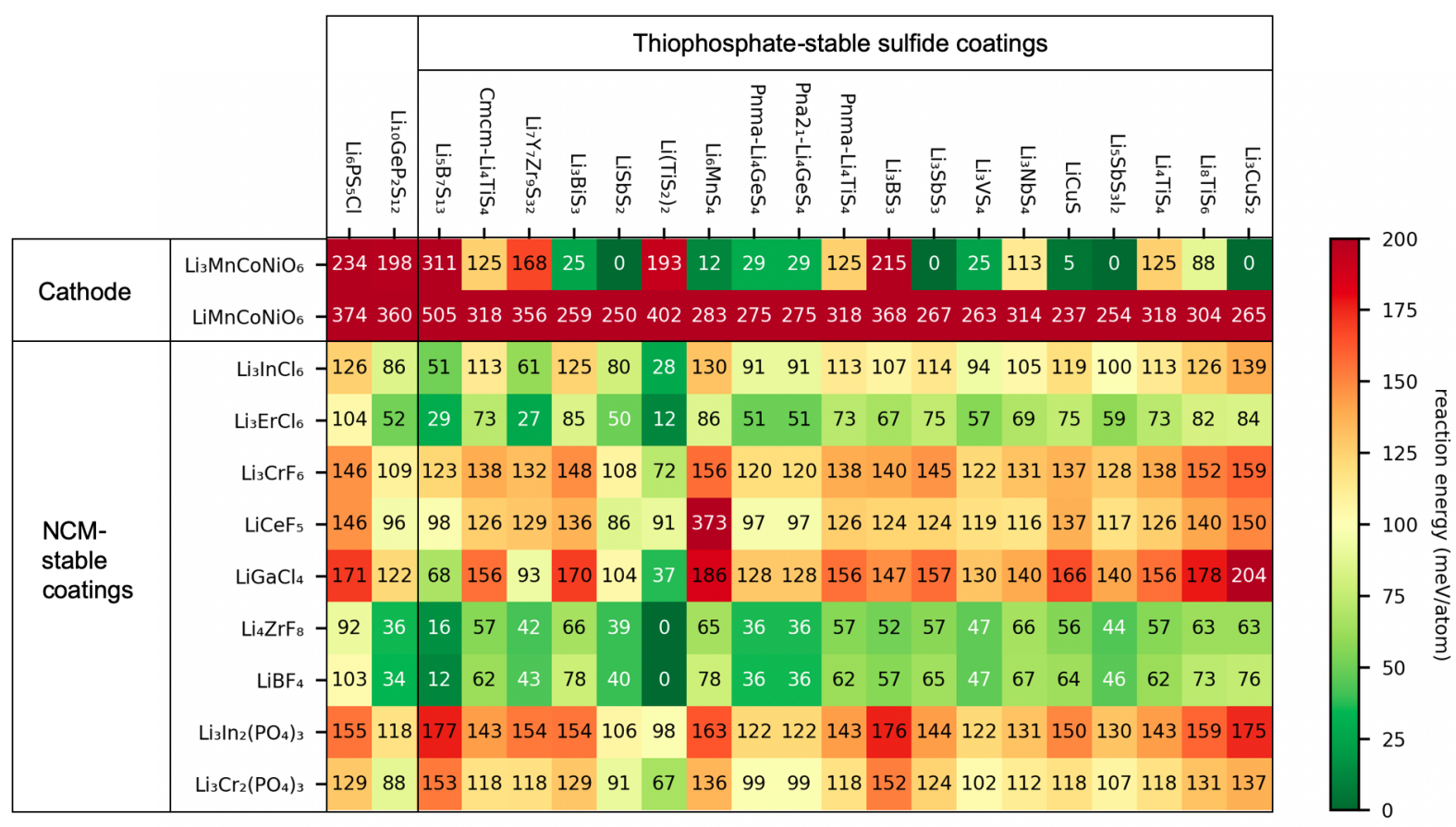

Figure 4. Heat map of reaction energies at possible interfaces in solid state batteries. Each value represents the maximal magnitude of the interfacial reaction energy among various interfaces in each half cell: cathode(charged/discharged)-coating, coating-coating and coating-solid electrolyte. The top left cells represent the direct contact between NCM cathode and thiophosphate electrolytes. The "thiophosphate-stable coatings" are predicted to have an interfacial reaction energy with both thiophosphate electrolytes no less than $-30 \mathrm{meV} / \mathrm{atom}$, and the "NCM-stable coatings" are predicted to have an interfacial reaction energy with both charged and discharged NCM no less than $-30 \mathrm{meV} /$ atom.

Table 3. Interfacial reaction energies (meV/atom) between the solid electrolyte candidate materials and the anodes.

\begin{tabular}{|c|c|c|c|c|c|}
\hline \multicolumn{2}{|c|}{} & \multicolumn{2}{|c|}{ Sulfides } & \multicolumn{2}{c|}{ Thiophosphates } \\
\cline { 3 - 6 } & $\mathrm{Li}_{5} \mathrm{~B}_{7} \mathrm{~S}_{13}$ & $\mathrm{Li}_{7} \mathrm{Y}_{7} \mathrm{Zr}_{9} \mathrm{~S}_{32}$ & $\mathrm{Li}_{10} \mathrm{GeP}_{2} \mathrm{~S}_{12}$ & $\mathrm{Li}_{6} \mathrm{PS}_{5} \mathrm{Cl}$ \\
\hline \multirow{3}{*}{ Anode } & $\mathrm{Li}$ & -738.4 & -362.8 & -647.5 & -539.3 \\
\cline { 2 - 6 } & $\mathrm{LiC}_{6}$ & -194.8 & -148.2 & -186.9 & -173.7 \\
\cline { 2 - 6 } & $\mathrm{C}$ & 0 & 0 & 0 & 0 \\
\hline
\end{tabular}




\section{CONCLUSIONS}

Computational screening identified specific combinations of sulfides and halides that could yield a double-layer cathode coating with high ionic conductivity and excellent interface compatibility in solid-state batteries. We find the coating pairs $\mathrm{Li}_{5} \mathrm{~B}_{7} \mathrm{~S}_{13}-\mathrm{Li}_{3} \mathrm{ErCl}_{6}, \mathrm{Li}\left(\mathrm{TiS}_{2}\right)_{2}-\mathrm{Li}_{3} \mathrm{InCl}_{6}$, $\mathrm{Li}_{7} \mathrm{Y}_{7} \mathrm{Zr}_{9} \mathrm{~S}_{32}-\mathrm{Li}_{3} \mathrm{ErCl}_{6}$, and $\mathrm{Li}\left(\mathrm{TiS}_{2}\right)_{2}-\mathrm{Li}_{3} \mathrm{ErCl}_{6}$ to be particularly promising, as the ionic conductivity could remain close to the value of the original solid electrolyte and there is a low thermodynamic driving force for chemical reactions at all interfaces. Furthermore, the high ionic conductivity and improved electrochemical stability predicted in the two sulfide materials $\mathrm{Li}_{5} \mathrm{~B}_{7} \mathrm{~S}_{13}$ and $\mathrm{Li}_{7} \mathrm{Y}_{7} \mathrm{Zr}_{9} \mathrm{~S}_{32}$ suggest they may be alternatives to the best-known thiophosphate solid electrolytes.

\section{ACKNOWLEDGMENTS}

This work is funded by Toyota Motor Corporation. The authors acknowledge the computational resources provided by the Maryland Advanced Research Computing Center (MARCC).

\section{REFERENCES}

1. Y. Nishi, $J$ Power Sources, 2001, 100, 101-106.

2. V. Etacheri, R. Marom, R. Elazari, G. Salitra and D. Aurbach, Energy \& Environmental Science, 2011, 4.

3. J. Schnell, T. Günther, T. Knoche, C. Vieider, L. Köhler, A. Just, M. Keller, S. Passerini and G. Reinhart, J Power Sources, 2018, 382, 160-175.

4. $\quad$ K. N. Jung, H. S. Shin, M. S. Park and J. W. Lee, ChemElectroChem, 2019, 6, 38423859 .

5. K. Liu, Y. Liu, D. Lin, A. Pei and Y. Cui, Sci Adv, 2018, 4, eaas9820.

6. A. Manthiram, X. Yu and S. Wang, Nature Reviews Materials, 2017, 2.

7. J. C. Bachman, S. Muy, A. Grimaud, H. H. Chang, N. Pour, S. F. Lux, O. Paschos, F. Maglia, S. Lupart, P. Lamp, L. Giordano and Y. Shao-Horn, Chem Rev, 2016, 116, 140162.

8. K. Nie, Y. Hong, J. Qiu, Q. Li, X. Yu, H. Li and L. Chen, Front Chem, 2018, 6, 616.

9. A. Sakuda, A. Hayashi and M. Tatsumisago, Sci Rep, 2013, 3, 2261.

10. Z. Zhang, Y. Shao, B. Lotsch, Y.-S. Hu, H. Li, J. Janek, L. F. Nazar, C.-W. Nan, J. Maier, M. Armand and L. Chen, Energy \& Environmental Science, 2018, 11, 1945-1976.

11. A. M. Nolan, Y. Zhu, X. He, Q. Bai and Y. Mo, Joule, 2018, 2, 2016-2046.

12. Y. Xiao, L. J. Miara, Y. Wang and G. Ceder, Joule, 2019, 3, 1252-1275.

13. Y. Z. Zhu, X. F. He and Y. F. Mo, J Mater Chem A, 2016, 4, 3253-3266.

14. Y. Z. Zhu, X. F. He and Y. F. Mo, Acs Appl Mater Inter, 2015, 7, 23685-23693.

15. A. Sakuda, A. Hayashi and M. Tatsumisago, Chemistry of Materials, 2010, 22, 949-956.

16. W. Zhang, F. H. Richter, S. P. Culver, T. Leichtweiss, J. G. Lozano, C. Dietrich, P. G. Bruce, W. G. Zeier and J. Janek, ACS Appl Mater Interfaces, 2018, 10, 22226-22236.

17. C. Wang, K. Aoyagi, M. Aykol and T. Mueller, ACS Appl Mater Interfaces, 2020, 12, 55510-55519.

18. X. Li, L. Jin, D. Song, H. Zhang, X. Shi, Z. Wang, L. Zhang and L. Zhu, Journal of Energy Chemistry, 2020, 40, 39-45. 
19. N. Ohta, K. Takada, I. Sakaguchi, L. Zhang, R. Ma, K. Fukuda, M. Osada and T. Sasaki, Electrochem Commun, 2007, 9, 1486-1490.

20. Y. Seino, T. Ota and K. Takada, J Power Sources, 2011, 196, 6488-6492.

21. A. Sakuda, H. Kitaura, A. Hayashi, K. Tadanaga and M. Tatsumisago, J Power Sources, 2009, 189, 527-530.

22. Y. Ito, Y. Sakurai, S. Yubuchi, A. Sakuda, A. Hayashi and M. Tatsumisago, Journal of The Electrochemical Society, 2015, 162, A1610-A1616.

23. K. Takada, N. Ohta, L. Zhang, K. Fukuda, I. Sakaguchi, R. Ma, M. Osada and T. Sasaki, Solid State Ionics, 2008, 179, 1333-1337.

24. S. Yubuchi, Y. Ito, T. Matsuyama, A. Hayashi and M. Tatsumisago, Solid State Ionics, 2016, 285, 79-82.

25. F. Han, J. Yue, C. Chen, N. Zhao, X. Fan, Z. Ma, T. Gao, F. Wang, X. Guo and C. Wang, Joule, 2018, 2, 497-508.

26. H. W. Kwak and Y. J. Park, Sci Rep, 2019, 9, 8099.

27. S. Ito, S. Fujiki, T. Yamada, Y. Aihara, Y. Park, T. Y. Kim, S.-W. Baek, J.-M. Lee, S. Doo and N. Machida, J Power Sources, 2014, 248, 943-950.

28. A. M. Nolan, Y. Liu and Y. Mo, ACS Energy Letters, 2019, 4, 2444-2451.

29. D. H. Snydacker, V. I. Hegde and C. Wolverton, Journal of the Electrochemical Society, 2017, 164, A3582-A3589.

30. T. Chen, G. Ceder, G. Sai Gautam and P. Canepa, Front Chem, 2019, 7, 24.

31. T. Chen, G. Sai Gautam and P. Canepa, Chemistry of Materials, 2019, 31, 8087-8099.

32. M. Aykol, S. Kim, V. I. Hegde, D. Snydacker, Z. Lu, S. Q. Hao, S. Kirklin, D. Morgan and C. Wolverton, Nat Commun, 2016, 7.

33. S. Yu, H. Park and D. J. Siegel, ACS Appl Mater Interfaces, 2019, 11, 36607-36615.

34. S. Muy, J. C. Bachman, L. Giordano, H. H. Chang, D. L. Abernathy, D. Bansal, O. Delaire, S. Hori, R. Kanno, F. Maglia, S. Lupart, P. Lamp and Y. Shao-Horn, Energy \& Environmental Science, 2018, 11, 850-859.

35. J. Lau, R. H. DeBlock, D. M. Butts, D. S. Ashby, C. S. Choi and B. S. Dunn, Advanced Energy Materials, 2018, 8.

36. S. P. Culver, R. Koerver, W. G. Zeier and J. Janek, Advanced Energy Materials, 2019, 9.

37. G. Henkelman, B. P. Uberuaga and H. Jonsson, Journal of Chemical Physics, 2000, 113, 9901-9904.

38. G. Henkelman and H. Jonsson, Journal of Chemical Physics, 2000, 113, 9978-9985.

39. X. F. He, Y. Z. Zhu, A. Epstein and Y. F. Mo, Npj Computational Materials, $2018,4$.

40. X. Chen, X. Liu, X. Shen and Q. Zhang, Angew Chem Int Ed Engl, 2021, DOI: 10.1002/anie.202107369.

41. C. Wang, K. Aoyagi, P. Wisesa and T. Mueller, Chemistry of Materials, 2020, 32, 37413752.

42. G. Liu, Y. Lu, H. Wan, W. Weng, L. Cai, Z. Li, X. Que, H. Liu and X. Yao, ACS Appl Mater Interfaces, 2020, 12, 28083-28090.

43. N. Yabuuchi and T. Ohzuku, J Power Sources, 2003, 119-121, 171-174.

44. X. Li, J. Liang, X. Yang, K. R. Adair, C. Wang, F. Zhao and X. Sun, Energy \& Environmental Science, 2020, 13, 1429-1461.

45. A. Jain, G. Hautier, S. P. Ong, C. Moore, B. Kang, H. L. Chen, X. H. Ma, J. C. Kim, M. Kocher, D. Gunter, S. Cholia, A. Greiner, D. H. Bailey, D. Skinner, K. Persson and G. Ceder, Abstr Pap Am Chem S, 2012, 243. 
46. S. P. Ong, W. D. Richards, A. Jain, G. Hautier, M. Kocher, S. Cholia, D. Gunter, V. L. Chevrier, K. A. Persson and G. Ceder, Comp Mater Sci, 2013, 68, 314-319.

47. W. H. Sun, S. T. Dacek, S. P. Ong, G. Hautier, A. Jain, W. D. Richards, A. C. Gamst, K. A. Persson and G. Ceder, Sci Adv, 2016, 2.

48. G. Hautier, S. P. Ong, A. Jain, C. J. Moore and G. Ceder, Phys Rev B, 2012, 85.

49. W. D. Richards, L. J. Miara, Y. Wang, J. C. Kim and G. Ceder, Chemistry of Materials, 2015, 28, 266-273.

50. J. P. Perdew, M. Emzerhof and K. Burke, Journal of Chemical Physics, 1996, 105, 99829985.

51. P. E. Blochl, Physical Review B, 1994, 50, 17953-17979.

52. $\quad$ S. P. Ong, Y. F. Mo, W. D. Richards, L. Miara, H. S. Lee and G. Ceder, Energy \& Environmental Science, 2013, 6, 148-156.

53. Z. Y. Zhu, I. H. Chu and S. P. Ong, Chemistry of Materials, 2017, 29, 2474-2484.

54. A. V. Shapeev, Multiscale Modeling \& Simulation, 2016, 14, 1153-1173.

55. S. Plimpton, J. Comput. Phys., 1995, 117, 1-19.

56. E. V. Podryabinkin and A. V. Shapeev, Comp Mater Sci, 2017, 140, 171-180.

57. A. Marcolongo and N. Marzari, Physical Review Materials, 2017, 1.

58. N. J. J. de Klerk, E. van der Maas and M. Wagemaker, ACS Appl Energy Mater, 2018, 1, 3230-3242.

59. S. C. Yin, Y. H. Rho, I. Swainson and L. F. Nazar, Chemistry of Materials, 2006, 18, 1901-1910.

60. Y. W. Hu, I. D. Raistrick and R. A. Huggins, Journal of The Electrochemical Society, 2019, 124, 1240-1242.

61. B. Wang, B. C. Chakoumakos, B. C. Sales, B. S. Kwak and J. B. Bates, J Solid State Chem, 1995, 115, 313-323.

62. S. Xu, R. M. Jacobs, H. M. Nguyen, S. Hao, M. Mahanthappa, C. Wolverton and D. Morgan, J Mater Chem A, 2015, 3, 17248-17272.

63. M. T. Dunstan, J. M. Griffin, F. Blanc, M. Leskes and C. P. Grey, The Journal of Physical Chemistry C, 2015, 119, 24255-24264.

64. A. D. Sendek, E. R. Antoniuk, E. D. Cubuk, B. Ransom, B. E. Francisco, J. BuettnerGarrett, Y. Cui and E. J. Reed, ACS Appl Mater Interfaces, 2020, 12, 37957-37966.

65. Y. Ito, M. Otoyama, A. Hayashi, T. Ohtomo and M. Tatsumisago, J Power Sources, 2017, 360, 328-335.

66. Y. E. Choi, K. H. Park, D. H. Kim, D. Y. Oh, H. R. Kwak, Y. G. Lee and Y. S. Jung, ChemSusChem, 2017, 10, 2605-2611.

67. A. D. Sendek, E. R. Antoniuk, E. D. Cubuk, B. E. Francisco, J. Buettner-Garrett, Y. Cui and E. J. Reed, 2019.

68. R. Kanno, Solid State Ionics, 2000, 130, 97-104.

69. S. Huber, C. Preitschaft, R. Weihrich and A. Pfitzner, Zeitschrift für anorganische und allgemeine Chemie, 2012, 638, 2542-2548.

70. S. Muy, J. Voss, R. Schlem, R. Koerver, S. J. Sedlmaier, F. Maglia, P. Lamp, W. G. Zeier and Y. Shao-Horn, iScience, 2019, 16, 270-282.

71. X. Li, J. Liang, J. Luo, M. Norouzi Banis, C. Wang, W. Li, S. Deng, C. Yu, F. Zhao, Y. Hu, T.-K. Sham, L. Zhang, S. Zhao, S. Lu, H. Huang, R. Li, K. R. Adair and X. Sun, Energy \& Environmental Science, 2019, 12, 2665-2671. 
72. A. B. Slobodyuk, V. Y. Kavun and N. A. Didenko, Journal of Structural Chemistry, 2013, 54, 168-173.

73. A. Ivanov-Schitz, Solid State Ionics, 2001, 139, 153-157.

74. Y. Naganovsky and S. Sigaryov, Solid State Ionics, 1992, 50, 1-9.

75. Y. Zhao, K. Zheng and X. Sun, Joule, 2018, 2, 2583-2604.

76. A. Sakuda, T. Takeuchi and H. Kobayashi, Solid State Ionics, 2016, 285, 112-117.

77. H. Kitaura, A. Hayashi, K. Tadanaga and M. Tatsumisago, Solid State Ionics, 2011, 192, 304-307. 